\title{
LA-UR- $98-4566$
}

Title:

Optimizing the Ranchero Coaxial F1ux Compression Generator*

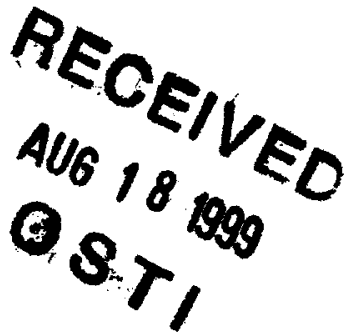

Author(s): D.G. Tasker, J.H. Goforth, C.M. Fowler, E.A. Lopez, H. Oona, J.C. King, D.H. Herrera, D.T. Torres, R.E. Reinovsky, E.C. Martinez, J.L. Stokes, L.J. Tabaka, O.F. Garcia, W.L. Atchison, R.J. Faehl, I.R. Lindemuth, R.K. Keinigs, and P.J. Miller

VIIIth International Conference on Megagauss Field Generation and Related Topics, October 18-23, 1998; Ta11ahassee, Florida, USA.

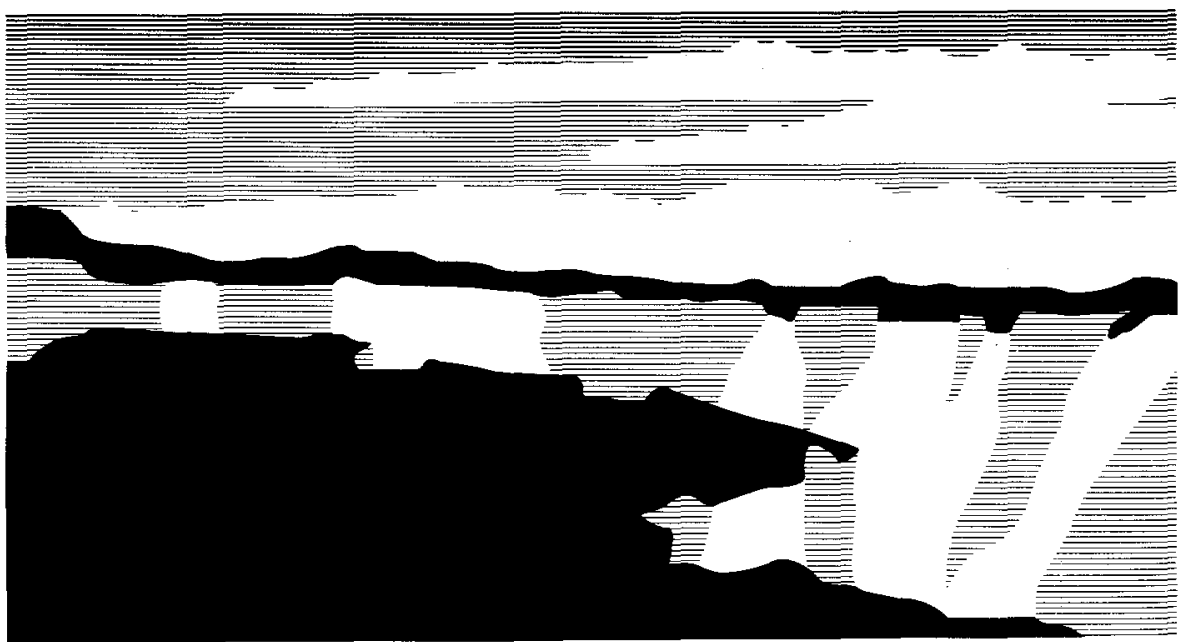

Los Alamos National Laboratory, an affirmative action/equal opportunity employer, is operated by the University of California for the U.S. Department of Energy under contract W-7405-ENG-36. By acceptance of this article, the publisher recognizes that the U.S. Government retains a nonexclusive, royalty-free license to publish or reproduce the published form of this contribution, or to allow others to do so, for U.S. Government purposes. The Los Alamos National Laboratory requests that the publisher identify this article as work performed under the auspices of the U.S. Department of Energy. 


\section{DISCLAIMER}

This report was prepared as an account of work sponsored by an agency of the United States Government. Neither the United States Government nor any agency thereof, nor any of their employees, make any warranty, express or implied, or assumes any legal liability or responsibility for the accuracy, completeness, or usefulness of any information, apparatus, product, or process disclosed, or represents that its use would not infringe privately owned rights. Reference herein to any specific commercial product, process, or service by trade name, trademark, manufacturer, or otherwise does not necessarily constitute or imply its endorsement, recommendation, or favoring by the United States Government or any agency thereof. The views and opinions of authors expressed herein do not necessarily state or reflect those of the United States Government or any agency thereof. 


\section{DISCLAIMER}

Portions of this document may be illegible in electronic image products. Images are produced from the best available original document. 
Technical Information Release Continued:

1. AUTHOR(S) (Full name and group affiliation)

Robert E. Reinovsky, DX-DO

Ernesto C. Martinez, DX-1

John L. Stokes, P-22

Leonard J. Tabaka, P-22

Otoniel F. Garcia, P-22

Walter L. Atchison, X-PA

Rickey J. Faehl, X-PA

Irvin R. Lindemuth, X-PA

Rhonald K. Keinigs, X-PA

Phillip J. Miller, NAWC 


\title{
Optimizing the Ranchero Coaxial Flux Compression Generator
}

\author{
D.G. Tasker, J.H. Goforth, W.L. Atchison, C.M. Fowler, \\ D.H. Herrera, J.C. King, I.R. Lindemuth, E.A. Lopez, \\ E.C. Martinez, H. Oona, R.E. Reinovsky, J. Stokes, \\ L.J. Tabaka, and D.T. Torres \\ University of California, Los Alamos National Laboratory, \\ Los Alamos, New Mexico 87545

\section{P.J. Miller} \\ Naval Air Warfare Center, Weapons Division, \\ China Lake, California 93555-6001
}

\begin{abstract}
Ranchero is an explosively driven magnetic flux-compression generator that has been developed, over the last four years, as a versatile power source for high energy density physics experiments. It is coaxial, and comprises a $15 \mathrm{~cm}$-diameter armature and a $30-\mathrm{cm}$ stator, each aluminum. The length may be varied to suit the demands of each experiment; thus far, lengths of $0.43 \mathrm{~m}$ and $1.4 \mathrm{~m}$ have been used. The stator is filled and driven by a highperformance cast explosive, and the ultimate performance of the device is limited by the smoothness of the armature expansion.

The armature explosive is initiated on axis by PETN hemispheres, spaced at intervals of between $18 \mathrm{~mm}$ and $24.5 \mathrm{~mm}$; each is simultaneously detonated by a slapper detonator system. Calculations of armature expansion predicted ripples less than $0.2 \mathrm{~mm}$, and this was confirmed in early experiments. Yet, ripples approaching tens of millimeters were observed in some more recent experiments. We will discuss the possible origins of these large ripples, and the methods we have used to correct them.

\section{Introduction}

The Ranchero system has been described in detail previously. ${ }^{1,2}$ To provide the electrical energy to be used for imploding liner tests, a single module with an end output configuration has been developed. The module is $0.43-\mathrm{m}$ long and expands the armature by a factor of two to reach the 30-cm OD stator. The experiments are conducted in the range of 30-48 MA currents. The modules are filled with high explosive PBXN-110 charges, 43-cm long. We have performed tests and related ID MHD calculations at the 48-MA current level with small loads. From these results, we determine that we can deliver currents of approximately $50 \mathrm{MA}$ to loads of $8 \mathrm{nH}$ with the 1.4-m modules.
\end{abstract}

\footnotetext{
- This work was supported by the U.S. Department of Energy
} 
The armature for Ranchero is 6-mm-thick aluminum wall with an outer diameter of $15.2 \mathrm{~cm}$, and the total length can be varied from $140 \mathrm{~cm}$ to $43 \mathrm{~cm}$, dependent on the electrical requirements of the load. Two slapper detonator cables, placed back to back, initiate detonation of the explosive charges within the armature, each with 56 discrete points (total of 112 points) placed $24.5 \mathrm{~mm}$ apart. Current gain in this device is limited by the residual inductance that remains after the armature has reached the stator. In a $43 \mathrm{~cm}$ generator with $0.5 \mathrm{~mm}$ insulation the residual inductance is $1.11 \mathrm{nH}$, at least $0.7 \mathrm{nH}$ of which is due to insulation and diffusion. This means that at worst we achieve an overall gap of $0.8 \mathrm{~mm}$. Clearly, this gap, and therefore the residual inductance, strongly depends on the smoothness (ripple) of the armature surface. ${ }^{2}$ Consequently, it is important to achieve the smoothest an outer surface.

Using a 2D hydrodynamic code, MESA-2D, the thickness of a polymethyl-methacrylate (PMMA) smoothing layer was adjusted to achieve the smoothest armature expansion. Ripples of less than $0.2 \mathrm{~mm}$ were predicted, and this was confirmed by experiment. However, ripples approaching tens of millimeters were observed in a significant number of experiments. Figure 1 shows a high-speed photograph of one such experiment, where ripples of $\sim 10 \mathrm{~mm}$ were observed.

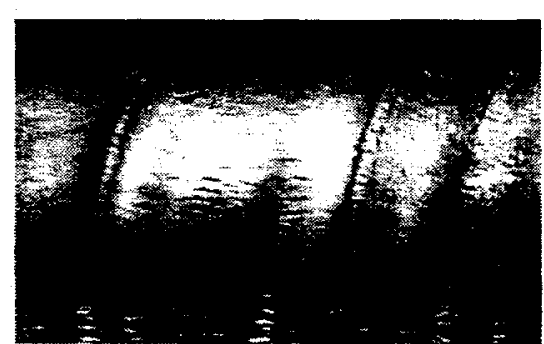

Figure 1. Photograph of armature ripple.

\section{Origins of Ripple}

We hypothesized various possible causes of the large ripple, including the quality of the explosive; its age; the manufacture of the slapper system; the type of PETN booster; and the electrical system that powers the slappers; and point failure. A database was assembled for tens of experiments to identify the possible culprit, but no clear pattern of failure was detected.

The slapper system was tested repeatedly - without the surrounding PBXN-110 - with many variations in electrical drive, yet with no obvious failures, so this was quickly eliminated as a culprit.

\section{Calculations of Armature Expansion}

One concern was that the initiation system for the explosive was barely adequate, thereby leading to the random failure of experiments. The MESA2D code could not model the growth of a reaction in the explosive to fulldetonation. ${ }^{3}$ Hence, we resorted to the use of the DYNA-2D code that has a well-calibrated reaction and growth routine for PBXN-110. ${ }^{4}$

The problem was modeled as a half-cylinder, with a 56-point hemispherical initiation system ( 56 above the z-axis, and 56 below), Fig. 2. The coaxial cylinders were filled with PBXN-110 throughout. We modeled both the 24.5- 


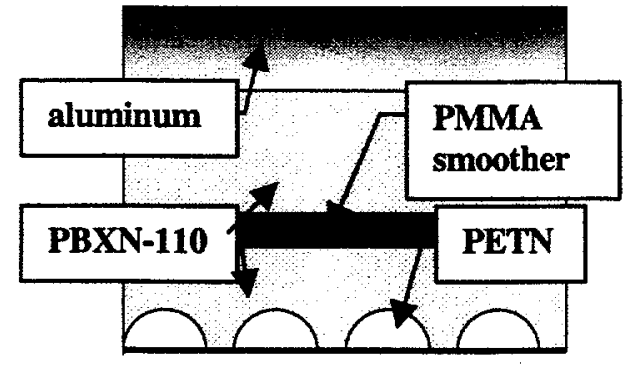

Figure 2. Initiation system schematic.

mm (with a 7-mm PMMA smoother) and 18-mm center-tocenter spacing (with a $6.35-\mathrm{mm}$ smoother), with the same outside radius. The questions addressed were: whether the PBXN-110 ignited promptly on the outside of the PMMA, i.e., what was the run distance to detonation; what was the ripple on outside surface of aluminum shell at the maximum radius (compared to MESA-2D predictions). We also studied the effect of deliberately preventing a PETN sphere from igniting (i.e., turning it off), and the effect of reducing the PETN pressing density from 1650 to $1550 \mathrm{~kg} / \mathrm{m}^{3}$.

\section{Computational Results}

The results of the DYNA-2D calculations, shown in Fig. 3, confirmed the MESA-2D results, i.e., that $\sim 0.2 \mathrm{~mm}$ ripples would be expected for the $18 \mathrm{~mm}$ spacing. Calculations of the ripple when a point was "turned-off," for the $24.5-\mathrm{mm}$ spacing, were especially interesting. Here the predicted ripple was $\sim 10 \mathrm{~mm}$, in good agreement with experimental results (in the bad experiments). This confirmed that a likely cause of the bad ripple was pointfailure. Neither the MESA nor DYNA-2D codes predicted that the pressing density of the PETN cups would have any effect on the initiation of the PBXN110 .

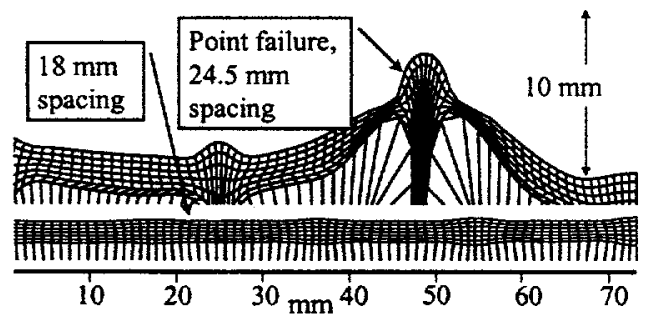

Figure 3. Calculated ripple showing single point failure (top) and correct expansion.

\section{Explosive}

We realized that one slapper design might allow the migration of the explosive ingredients to the PETN booster cups. The migration of certain materials is known to "poison" PETN, i.e., sufficiently contaminate the surface such that the PETN will not detonate. PBXN-110, is an explosive with a bimodal mixture of $88 \%$ by weight HMX ( $66 \%$ coarse $-279 \mu \mathrm{m}$ mean particle size, $22 \%$ fine $-39 \mu \mathrm{m}$ ), in a $12 \%$ HTPB polyurethane binder. ${ }^{5}$ Isodecyl pelargonate (IDP) is added to the HTPB binder to initiate curing of the binder, and has a history of migration problems. Consequently, the slapper cable was redesigned, to minimize the possibility of IDP migration, and tested by firing the Ranchero armature without the stator, as described in the next section 


\section{Camera experiments}

High-speed camera experiments were fired in which two separate armatures were fired end-to-end in the same experiment, one with the standard PETN booster, and one with a two-component pressing (PETN and LX-106). The observed ripple was significantly reduced in both armatures, i.e.; the results confirmed that IDP migration was responsible for the poisoning of the PETN pellets. The conventional PETN $\left(1550 \mathrm{~kg} / \mathrm{m}^{3}\right)$ pressing had ripples of $\sim 1 \mathrm{~mm}$, whereas the two-component pressing had ripples of $<0.2 \mathrm{~mm}$. This was clear evidence that the low density $\left(1550 \mathrm{~kg} / \mathrm{m}^{3}\right)$ PETN was not providing the necessary stimulus to promptly detonate PBXN-110. Both of the codes had failed to predict this poor initiation of the PBXN-110 by the $1550 \mathrm{~kg} / \mathrm{m}^{3}$ PETN.

\section{Summary and Conclusions}

The results of a series of experiments and computer calculations suggest that there are two independent causes of large ripple in the armature expansion. There is substantial evidence that we must design the combined slapper and explosive system to prevent IDP migration and the consequent point failures. These point failures are responsible for ripples of $\sim 10 \mathrm{~mm}$ or more. There is also clear evidence that the reduction of the PETN booster density from 1650 to $1550 \mathrm{~kg} / \mathrm{m}^{3}$ causes a smaller ripple of $\sim 1 \mathrm{~mm}$, probably because of inadequate initiation of the PBXN-110 explosive - although the computer analyses failed to predict this. We expect to verify these findings and fixes with camera tests to be performed in the coming weeks.

\section{References}

${ }^{1}$ Goforth, J.H., et al., Ranchero: A High Current Flux Compression Generator System For Heavy Liner Experiments, Seventh Conference on the Generation of Megagauss Magnetic Fields, 1996.

${ }^{2}$ Goforth, J.H., et al., The Ranchero Explosive Pulsed Power System, Eleventh IEEE Int. Pulsed Power Conference, Baltimore, MD, 1997, 573.

${ }^{3}$ Lee, E.L. and Tarver, C.M., Phys. Fluids, 23, 2362 (1980).

${ }^{4}$ Miller, P.J. and Sutherland, G.T., Reaction Rate Modeling of PBXN-110, Shock Compression of Condensed Matter - 1995, 413, Seattle, WA, Aug 1995. AIP Conference Procs. 370.

${ }^{5}$ Lemar, E.R., Forbes, J.W., and Sutherland, G.T, Detonation Wave Velocity and Curvature of IRX-4 and PBXN-110, Shock Compression of Condensed Matter - 1995, 791, ibid.

${ }^{6}$ LX-10: HMX, Viton A (95:5 by weight) 